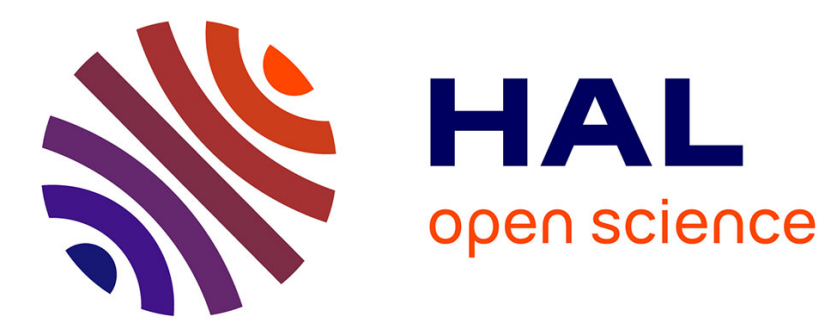

\title{
Insights into the crystal structure, polymorphism and thermal behavior of menthol optical isomers and racemates
}

\author{
Yohann Corvis, Philippe Négrier, Stéphane Massip, Jean-Michel Leger, \\ Philippe Espeau
}

\section{To cite this version:}

Yohann Corvis, Philippe Négrier, Stéphane Massip, Jean-Michel Leger, Philippe Espeau. Insights into the crystal structure, polymorphism and thermal behavior of menthol optical isomers and racemates. CrystEngComm, 2012, 14 (20), pp.7055-7064. 10.1039/c2ce26025e . hal-00738241

\section{HAL Id: hal-00738241 \\ https://hal.science/hal-00738241}

Submitted on 4 Jan 2018

HAL is a multi-disciplinary open access archive for the deposit and dissemination of scientific research documents, whether they are published or not. The documents may come from teaching and research institutions in France or abroad, or from public or private research centers.
L'archive ouverte pluridisciplinaire HAL, est destinée au dépôt et à la diffusion de documents scientifiques de niveau recherche, publiés ou non, émanant des établissements d'enseignement et de recherche français ou étrangers, des laboratoires publics ou privés. 


\title{
Insights into the crystal structure, polymorphism and thermal behavior of menthol optical isomers and racemates
}

\author{
Yohann Corvis, ${ }^{* a}$ Philippe Ne'grier, ${ }^{b}$ Ste $^{\prime}$ phane Massip, ${ }^{c}$ Jean-Michel Leger ${ }^{c}$ and Philippe Espeau ${ }^{a}$
}

The physico chemical properties of the levo and dextrorotatory menthol isomers as well as the corresponding racemic compound were studied using $\mathrm{X}$ ray single crystal or powder diffraction and differential scanning calorimetry experiments. As a result, the not yet determined crystal structure of DL menthol was solved. Moreover, the stable and metastable experimental temperature composition phase diagrams of the $\mathrm{L}$ menthol/D menthol binary system were determined. The thermodynamic relative stability of the different menthol polymorphs was also established. The present paper provides new physical, chemical and thermodynamic data of L, D and DL menthol and offers new insight into their polymorphism as well as into the levorotatory dextrorotatory menthol interactions. Both the thermodynamic and crystallographic approaches demonstrate unambiguously that racemic menthol is a racemate.

\section{Introduction}

Polymorph screening of molecular crystals has become one of the major challenges in chemical research. ${ }^{13}$ As a substance may present different crystalline forms with given properties, such as solubility, melting point and lattice structure, its most appro priate form has to be identified, classified and then considered. Polymorphism examples are diverse and the fields in which they manifest themselves are many. One can quote, for instance, cellulose or polycaproamide treatments in textile manufactur ing, ${ }^{4,5} \mathrm{~L}$ glutamic acid in the food industry, ${ }^{6}$ triglycerides for cosmetic applications ${ }^{79}$ and the carbamazepine nicotinamide cocrystal in the pharmaceutical field. ${ }^{10}$ The latter field is particularly connected to polymorphism issues since bioavail ability and toxicology are directly impacted by the nature of the crystalline active pharmaceutical ingredients. Even so, the polymorphism of many materials is unknown or not well known. In the present work, we focus on menthol, a monoterpene cyclohexanol which is widely used in todays world because of its pleasant smell, flavor and cooling property. Paradoxically, little physical and chemical data on menthol is available in the literature. Besides, with one asymmetric carbon atom, menthol

${ }^{a}$ Laboratoire Physico Chimie Industrielle du Médicament, EA 4066, Université Paris Descartes, Sorbonne Paris Cité, Faculté des Sciences Pharmaceutiques et Biologiques, 4 Avenue de l'bservatoire, Paris, 75006, France.E mail: yohann.corvis@parisdescartes.fr; Fax: +331706494 47; Tel: +33153739680

${ }^{b}$ Univ. Bordeaux, LOMA, UMR 5798, F 33400 Talence, France, and CNRS, LOMA, UMR 5798, F 33400 Talence, France

${ }^{c}$ Univ. Bordeaux, Pharmacochimie, FRE CNRS 3396, F 33000 Bordeaux, France, and CNRS, Pharmacochimie, FRE CNRS 3396, F 33000

Bordeaux, France can exist as two enantiomers, namely levorotatory (L ) and dextrorotatory menthol (D menthol). The main form of menthol found in nature is L menthol, which can be extracted from Mentha species such as $M$. piperita. ${ }^{11}$ Unlike the former optical isomer, D menthol is mainly obtained by chemical synthesis. The D enantiomer can be employed as a substitute for or a complement to natural menthol. ${ }^{12}$ As far as DL menthol, an equimolar mixture of $\mathrm{D}$ and $\mathrm{L}$ menthol, is concerned there is clearly a lack of information regarding its crystalline structure or concise thermodynamic data. This observation is all the more surprising since this compound is often employed in various industrial fields. Moreover, the polymorphism of menthol is barely known.

In the early twentieth century, by taking into consideration the morphological shapes of the crystals and their corresponding melting points, Fred E. Wright qualitatively identified four polymorphs of levorotatory menthol, called the $\alpha, \beta, \gamma$ and $\delta$ forms. ${ }^{13}$ Nevertheless, thus far, no quantitative study related to L menthol polymorphism has been carried out and DL menthol polymorphism remains unknown. Furthermore, the interactions between the two antipodes and the equimolar compound were estimated three decades ago. ${ }^{14}$ The proposed stable binary phase diagram was explained in terms of isotrimorphism of the enantiomers, leading to Roozeboom melting diagrams. There fore, the authors described DL menthol as a racemic mixed crystal undergoing three crystal modifications with monotropic behavior. The stable pseudo racemate was thus described as a Roozeboom's type II solid solution coming from the lowest melting form of the antipodes. However, no thermodynamic data related to the metastable forms were determined for the antipodes or for DL menthol. So far, our group has provided only an estimation of the $\mathrm{L}$ menthol polymorph heat of fusion. ${ }^{15}$ 
The lack of such miscellaneous data on menthol physico chemical properties led us to re examine in the present work the interactions between the levorotatory and dextrorotatory menthol molecules via the stable and metastable binary phase diagrams in the whole range of mole fractions. Accordingly, $\mathrm{X}$ ray powder diffraction (XRPD) experiments were performed with complementary thermal analyses in order to determine the nature of the binary interactions for the stable and metastable states. As far as racemic menthol is concerned, a slow sublimation condensation homemade device was specifically adapted in our lab to design convenient single crystals, allowing us to solve the DL menthol structure by $\mathrm{X}$ ray single crystal measurements for the first time.

Taken together, the results presented here bring new insights into the inter and intramolecular interactions in solid state menthol, especially for the equimolar compound in its stable and metastable states. A new stable binary phase diagram is proposed via the experimental thermodynamic data obtained for the metastable forms of both the antipode and racemic compounds.

\section{Materials and experiments}

\section{Materials}

L menthol (purity: 99.7\%; CAS 2216515 ) and D menthol (purity: $99.0 \%$; CAS 15356704 ) were provided by Acros Organics and DL menthol (purity $\geqslant 98.0 \%$; CAS 89781 ) by Alfa Aesar. No further purification was necessary.

\section{Preparation of the racemic menthol single-crystals}

DL menthol single crystals were prepared by sublimation con densation within a Pyrex ${ }^{\mathbb{R}}$ glass tube using a temperature gradient tubular oven. The powder was introduced at the end of the tube ( $\sim 40 \mathrm{~cm}$ length). After a second order vacuum was established in the tube, the latter was sealed in a flame and then placed in the temperature gradient tubular oven. The highest temperature was established at $32{ }^{\circ} \mathrm{C}$ and the coolest tempera ture at $80{ }^{\circ} \mathrm{C}$. After four weeks, whiskers could be observed in different parts of the tube. Their shapes and abundance depended on the condensation temperature.

\section{Macroscopic visualization of the racemic menthol single-crystals}

Without breaking the vacuum, pictures of the Pyrex ${ }^{\circledR}$ glass tube were taken at room temperature using a five megapixel CCD camera (Motic, Germany).

\section{Sample preparations for the DSC runs}

For the stable temperature composition $(T x)$ phase diagram, the menthol mixtures were obtained by mechanically mixing racemic and enantiomeric menthol in a mortar in a $3{ }^{\circ} \mathrm{C}$ cold room in order to limit the terpene sublimation process and/or local melting of the mixture due to mechanical friction. After one month of annealing at $3{ }^{\circ} \mathrm{C}$, the samples were analyzed by Differential Scanning Calorimetry (DSC).

The metastable levorotatory dextrorotatory menthol phase diagram was obtained after recrystallization was induced by the thermal quenching of the molten mixtures from 60 to $15{ }^{\circ} \mathrm{C}$ or $80{ }^{\circ} \mathrm{C}$ followed by a $5{ }^{\circ} \mathrm{C}$ min ${ }^{1}$ heating process.

\section{X-ray single-crystal diffraction}

A crystal $(150 \times 100 \times 100 \mu \mathrm{m})$ was trapped, without oil, by a MiTeGen MicroGripper ${ }^{\mathrm{TM}}$ and placed in a nitrogen environment at $50{ }^{\circ} \mathrm{C}$. A capillary was used in order to protect the crystal from the $\mathrm{N}_{2}$ flow. Data was collected with an $\mathrm{R}$ Axis Rapid Rigaku MSC diffractometer using $\mathrm{Cu} \mathrm{K} \alpha$ radiation and a Rigaku VariMax mirror. All the reflections were used for the unit cell refinement. The Mercury 2.2 program was used for the analysis and graphic representation. ${ }^{16}$ Other programs, such as Materials Studio Modeling 4.2 $2^{17}$ and ORTEP $32.02,{ }^{18}$ were also used to draw the molecular graphics. The crystal structure was solved by direct methods refined using the SHELX97 suite of programs. ${ }^{19}$ The positions of the $\mathrm{H}$ atoms were deduced from the coordinates of the non $\mathrm{H}$ atoms and confirmed by Fourier synthesis (with Uiso 1.2 Ueq of the corresponding $\mathrm{C}$ atom), except for the disordered $\mathrm{H}$ atoms of the hydroxyl groups, which were refined from the electronic density (with dfix at $0.84 \AA$ and Uiso $1.2 \mathrm{Ueq}$ of the corresponding $\mathrm{O}$ atom). The non $\mathrm{H}$ atoms were refined with anisotropic temperature parameters. All H atoms were included for the structure factor calculations.

\section{X-ray powder diffraction}

The experiments were performed with a horizontally mounted cylindrical position sensitive detector CPS 120 (Debye Scherrer geometry, transmission mode) from INEL, using $\mathrm{Cu} \mathrm{K} \alpha_{1}$ radiation ( $\lambda \quad 1.5406 \AA$ ). The samples were gently crushed before being introduced into Lindemann glass capillaries with a $0.5 \mathrm{~mm}$ inner diameter. Each capillary was sealed and then heated at $40{ }^{\circ} \mathrm{C}$ in order to melt the powder. After an in situ cooling process from 40 to $40{ }^{\circ} \mathrm{C}$ at $6{ }^{\circ} \mathrm{C} \mathrm{min}{ }^{1}$, high resolution XRPD patterns were measured at $40{ }^{\circ} \mathrm{C}$. The patterns were indexed using the peak picking option of the Materials Studio Modeling 4.2 software package. ${ }^{17}$ Potential solutions for the cell parameters and space group were found using the $\mathrm{X}$ cell algorithm. ${ }^{20}$ The cell parameters, including the unit cell parameters of the solid solutions from the binary mixtures with $\mathrm{L}$ menthol, were refined using a Pawley profile ${\text { fitting } \text { procedure. }^{21} \text { The Compass force field procedure }}^{22}$ was applied to get the best distances, angles and torsions in the molecule.

\section{Thermal analysis}

The temperatures and enthalpies of fusion were determined using a differential scanning calorimeter (Mettler Toledo, Switzerland) calibrated beforehand with high purity indium and zinc reference samples. DSC runs were performed at $5{ }^{\circ} \mathrm{C}$ min ${ }^{1}$ under an atmosphere of dry nitrogen gas. For more accurate statistics, the experiments on the pure menthol forms were reproduced at different scan rates and with different sample weights. The temperatures were determined at the onset of the thermograms for the pure compounds and the eutectic signals obtained for the enantiomer mixtures. The temperature of the binary mixture liquidus was obtained at the second peak position. As far as the solid solution is concerned, the solidus and liquidus temperatures 
were measured at the onset and peak of the single signal, respectively.

\section{Thermodynamic assessment}

The analysis of the phase diagrams, in the case of the binary equilibria between the mixed crystalline solid and liquid, was performed using the LIQFIT thermodynamic method. ${ }^{23}$ The excess quantities were determined by fitting the $T x$ experi mental results.

\section{Results and discussion}

\section{DL-menthol single-crystal structure}

Neither our knowledge nor the software tools at our disposal made it possible to solve the crystal structure of racemic menthol by Rietveld refinements of the powder diffraction pattern. Therefore, convenient single crystals of DL menthol were pre pared by a slow sublimation condensation process performed under a secondary vacuum. Fig. 1 shows the DL menthol single crystals recrystallizing as whiskers within a Pyrex ${ }^{\circledR}$ glass tube. The crystal structure of this compound was then solved by $\mathrm{X}$ ray single crystal diffraction (Cambridge Crystallographic Data Centre reference number 832350). The resulting data is listed in Table 1 . The corresponding $P \overline{1}$ triclinic unit cell is presented in Fig. 2. Three independent molecules can be seen. The intermolecular hydrogen bonds within the DL menthol crystal $(2.691(3)<d(\mathrm{O} \cdots \mathrm{O})<2.777(3) \AA$ and $152(5)<\mathrm{O} \mathrm{H} \cdots \mathrm{O}$ angle $<172(5)$ deg.) are slightly less strong than those measured by Bombicz and co workers for L menthol $(2.656(4)<d(\mathrm{O} \cdots \mathrm{O})<$ 2.678(5) $\AA$ and $165(3)<\mathrm{O} \mathrm{H} \cdots \mathrm{O}$ angle $<175(4)$ deg.). ${ }^{24}$ In addition, the hydrogen atom of the hydroxyl group is shared by two independent menthol entities. Such a complex structure may explain why it is difficult to obtain the crystal structure from the powder diffraction pattern.

According to Kuhnert Brandstaetter et al., the DL menthol structure should correspond to a racemic mixed crystal. ${ }^{14}$ Indeed, these authors suggested that the latter crystal corre sponds to a solid solution formed from the lowest melting temperature polymorph of each enantiomer (forms III and III'). The resulting melting loop with a maximum temperature implies that the mixed crystal has the same crystal system as polymorphs III and III'. Since the crystal structure of polymorph III has not

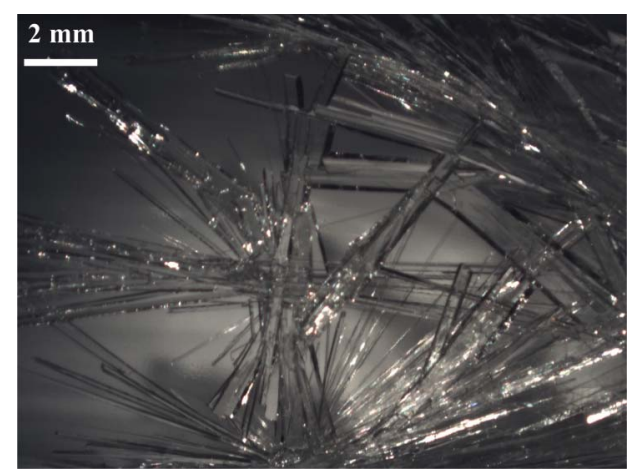

Fig. 1 Crystal shape of menthol after a slow sublimation condensation process under a secondary vacuum.
Table 1 DL menthol crystal data and structure refinement parameters obtained from the single crystal measurements

\begin{tabular}{|c|c|c|}
\hline Formula & & $\mathrm{C}_{10} \mathrm{H}_{20} \mathrm{O}$ \\
\hline $\mathrm{FW}\left(\mathrm{g} \mathrm{mol}^{1}\right)$ & & 156.26 \\
\hline Temperature & & $223 \mathrm{~K}$ \\
\hline Wavelength & & $1.54180 \AA$ \\
\hline Cryst. syst. & & Triclinic \\
\hline Space group & & $P 1$ \\
\hline \multirow[t]{2}{*}{ Unit cell dimensions } & Length $(\AA)$ & $\begin{array}{l}a=11.9521(10) \\
b=12.4769(12) \\
c=12.7864(10)\end{array}$ \\
\hline & Angle (deg.) & $\begin{array}{l}\alpha=117.498(5) \\
\beta=99.008(6) \\
\gamma=103.867(6)\end{array}$ \\
\hline Volume $\left(\AA^{3}\right)$ & & $1561.0(2)$ \\
\hline $\mathrm{Z}$ & & 6 \\
\hline$D_{\mathrm{c}}\left(\mathrm{g} \mathrm{cm}^{3}\right)$ & & 0.997 \\
\hline$\mu\left(\mathrm{mm}^{1}\right)$ & & 0.467 \\
\hline$R_{1}, I>2 \sigma(I)$ & & 0.0635 \\
\hline$w R_{2}, I>2 \sigma(I)$ & & 0.1509 \\
\hline$S$ & & 1.011 \\
\hline
\end{tabular}

yet been solved, one cannot conclude anything about the physical properties of DL menthol.

\section{Evidence and characterization of the L- and DL-menthol $\beta$ polymorphs}

The sublimation condensation experiments allowed us to distinguish another polymorphic form of DL menthol. Unfortunately, this polymorph was difficult to stabilize for reproducible studies. Polymorphism screening was thus per formed using quenching and annealing conditions, based on our previous work. ${ }^{15}$ Indeed, in the latter study, we demonstrated that $\alpha$ L menthol mixed with lidocaine may transform, under specific thermal conditions, into the $\beta \mathrm{L}$ menthol polymorph.

$\mathrm{X}$ ray powder diffraction experiments combined with thermal analyses allowed us to characterize the $\beta$ forms of both $\mathrm{L}$ and DL menthol. Manifestly, the polymorphic behavior of menthol molecules can be distinguished by quenching the molten pure component at low temperatures (Fig. 3). Temperatures in the range of 80 to $25^{\circ} \mathrm{C}$ were screened by thermal analysis. Indeed, after quenching the molten menthol to a lower temperature, DSC thermograms (heat flow $v$. temperature curves) were recorded upon heating (Fig. 3A, B), in order to provide feedback

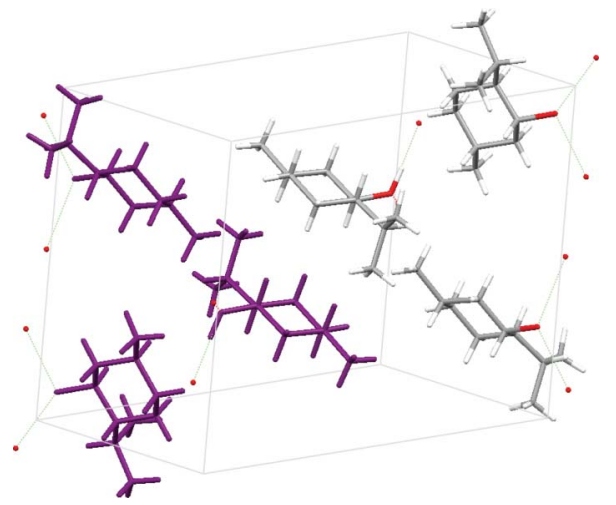

Fig. 2 Crystal structure of DL menthol. The 3 molecules in purple were obtained by symmetry of the asymmetric unit. The intermolecular hydrogen bonds are represented as green dotted lines. 
A
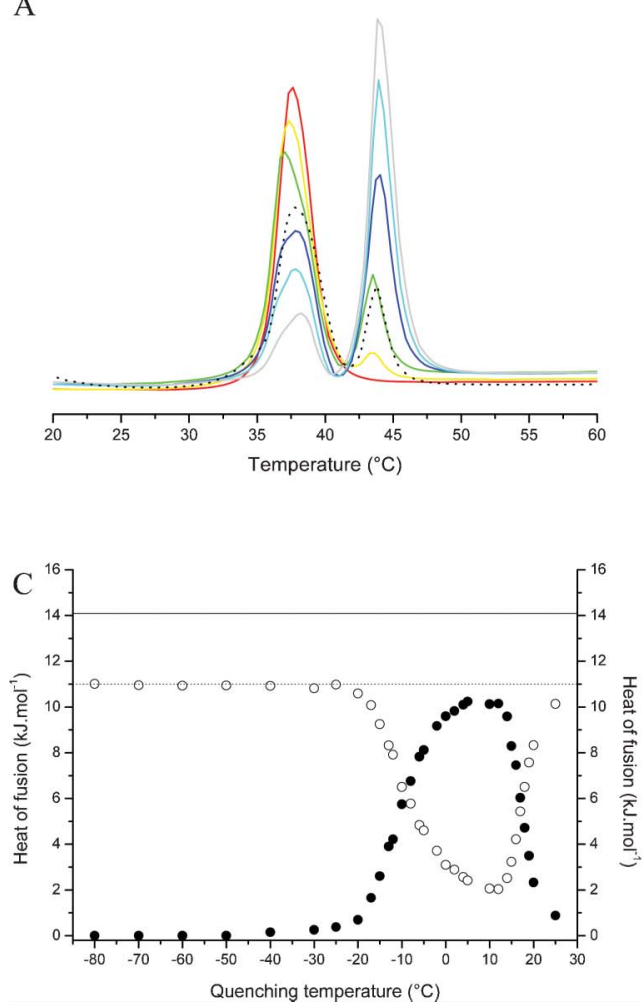

B
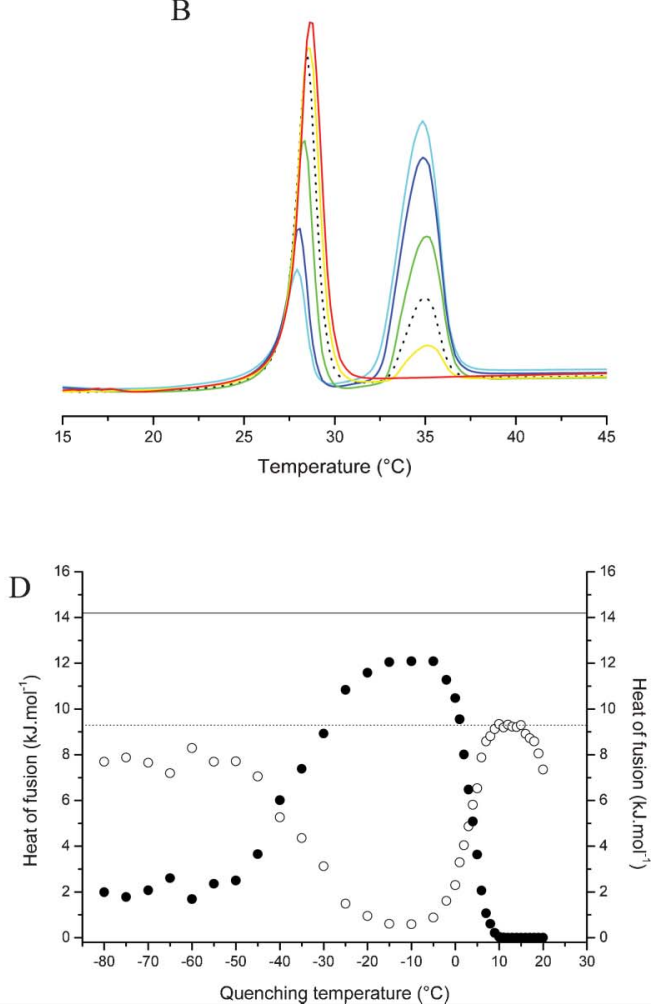

Fig. 3 Weight normalized DSC thermograms as a function of the quenching temperature from the menthol molten state (A, B), and the corresponding heats of fusion in $\mathrm{kJ}$ per mol of total menthol $(\mathrm{C}, \mathrm{D})$, which were measured for the $\alpha(\bullet)$ and $\beta(\bigcirc)$ polymorphs obtained after quenching. (A, C) L menthol, (B, D) DL menthol. For L menthol, an isotherm run was established for 5 min just after quenching. Scan rate: 20 and $10{ }^{\circ} \mathrm{C}$ min ${ }^{1}$ for $\mathrm{L}$ and DL menthol, respectively. (A) Quenching temperature in ${ }^{\circ} \mathrm{C}:-80$ (red line), -20 (yellow line), -15 (green line), -10 (dark blue line), -5 (cyan line), 5 (grey line), and $15(\cdots)$. (B) Quenching temperature in ${ }^{\circ} \mathrm{C}:-50(\cdots), 1$ (cyan line), 2 (dark blue line), 4 (green line), 7 (yellow line) and 15 (red line). (C, D) The heat of fusion measured for the pure $\alpha$ and $\beta$ menthol polymorphs are presented by the solid and dotted lines, respectively. Endothermic transformations give signals which point up.

for the solid state obtained as consequence to the thermal shock. Interestingly, L menthol presents a stable/metastable polymorph ratio that depends on the quenching temperature (Fig. 3A, C). The same tendency can be observed for DL menthol (Fig. 3B, D). A metastable form of levorotatory menthol was first evidenced by means of thermal analysis: the temperature and heat of fusion of $35.3{ }^{\circ} \mathrm{C}$, and $11.0 \mathrm{~kJ} \mathrm{~mol}{ }^{1}$, respectively. These results are in good agreement with the estimation that we proposed in a previous study, using the Schröder van Laar relation for the lidocaine $\mathrm{L}$ menthol interactions $\left(35.7^{\circ} \mathrm{C}\right.$ and $11.2 \mathrm{~kJ}$ mol $\left.{ }^{1}\right) .{ }^{15}$ The XRPD pattern obtained for this metastable form allows us to ascertain that it corresponds to the $\beta$ form. ${ }^{13,15}$ With a similar approach, the metastable form of racemic menthol highlighted in this study has been named the $\beta$ polymorph. The thermal data of the $\alpha$ and $\beta$ forms of $\mathrm{L}$ and DL menthol are displayed in Table 2 .

In order to have access to the life time of each $\beta$ polymorph, thermal experiments were performed as a function of time at the optimal temperature of their formation, i.e. $\quad 80$ and $+15^{\circ} \mathrm{C}$ for $\mathrm{L}$ and DL menthol, respectively. It is noteworthy that $\beta \mathrm{L}$ menthol is stable for at least $8 \mathrm{~h}$ at $80^{\circ} \mathrm{C}$ (results not shown), while $\beta$ DL menthol is rapidly transformed to its stable form at $15{ }^{\circ} \mathrm{C}$. Consequently, the evolution of the $\beta$ to $\alpha$ transition was followed as a function of the annealing time at the latter temperature (Fig. 4). The half life time of this polymorphic form at $15{ }^{\circ} \mathrm{C}$ is $23 \mathrm{~min}$. After $80 \mathrm{~min}$, the most important part of $\beta \mathrm{L}$ menthol is transformed into the $\alpha$ form.

All the annealing and kinetic studies presented above gave access to the ideal conditions regarding the $\mathrm{X}$ ray powder diffraction analyses of $\mathrm{L}$ and DL menthol $\beta$ polymorphs. Nevertheless, these conditions were slightly improved in order to obtain the best crystalline $\beta$ forms ( $c f$. the Materials and experiments section). The XRPD patterns corresponding to the stable and metastable forms of both $\mathrm{L}$ and DL menthol are proposed in Fig. 5. Since the fitting of the diffraction pattern

Table 2 Experimental temperatures and enthalpies of fusion for the $\alpha$ and $\beta$ polymorphs of L and DL menthol

\begin{tabular}{lllll}
\hline & $\alpha$ polymorph & \multicolumn{3}{c}{$\beta$ polymorph } \\
\hline & $T_{\text {fus }}\left( \pm 0.3^{\circ} \mathrm{C}\right)$ & $\Delta_{\text {fus }} H\left( \pm 0.2 \mathrm{~kJ} \mathrm{~mol}{ }^{1}\right)$ & $T_{\text {fus }}\left( \pm 0.3{ }^{\circ} \mathrm{C}\right)$ & $\Delta_{\text {fus }} H\left( \pm 0.2 \mathrm{~kJ} \mathrm{~mol}{ }^{1}\right)$ \\
L menthol & 42.9 & 14.1 & 35.3 & 1.0 \\
DL menthol & 33.8 & 14.2 & 27.3 & 9.3
\end{tabular}



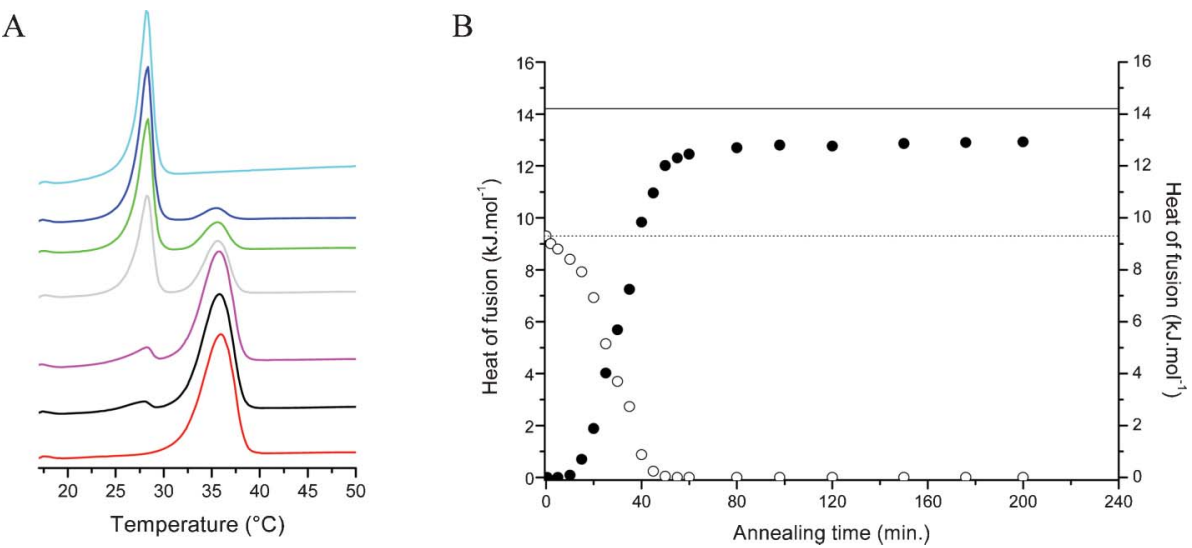

Fig. 4 DL menthol weight normalized DSC thermograms as a function of the annealing time at $15{ }^{\circ} \mathrm{C}$ from the molten state $(\mathrm{A})$, and the corresponding heats of fusion in $\mathrm{kJ}$ per mol of total menthol, which were measured for the $\alpha(\bullet)$, and $\beta(\bigcirc)$ polymorphs $(\mathrm{B})$. (A) Scan rate: $10^{\circ} \mathrm{C}$ min ${ }^{1}$. Annealing time in min: 5 (cyan line), 15 (dark blue line), 20 (green line), 25 (grey line), 40 (pink line), 50 (black line) and 60 (red line). Endothermic transformations give signals which point up. The thermograms were shifted for clarity. (B) The heat of fusion measured for the pure $\alpha$ and $\beta$ menthol polymorphs are presented by the solid and dotted lines, respectively.
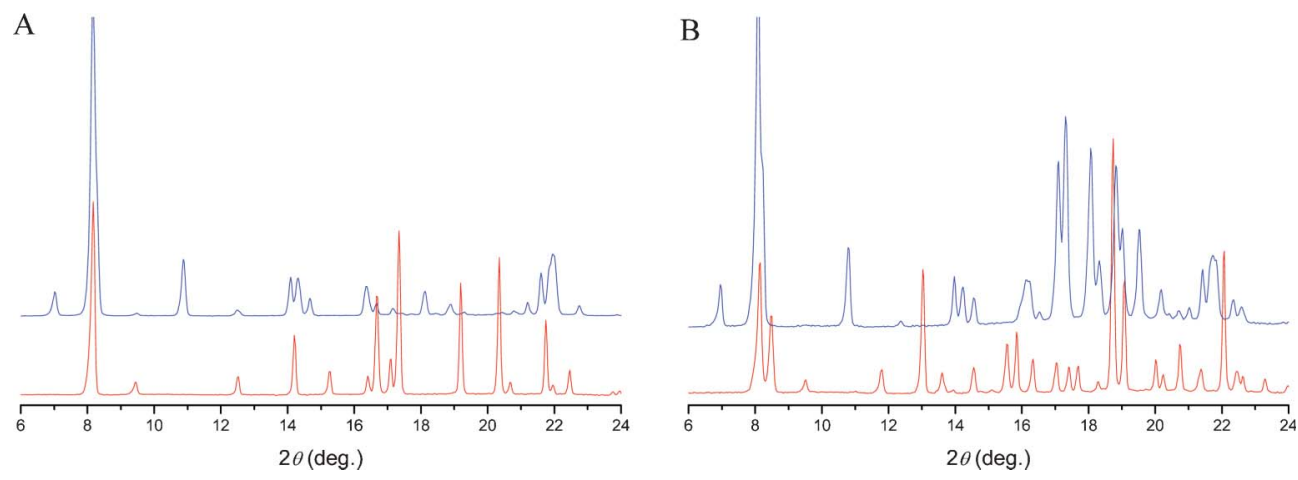

Fig. $5 \mathrm{X}$ ray powder diffraction patterns obtained for L (A), and DL menthol (B). The $\alpha$ menthol patterns recorded at $25^{\circ} \mathrm{C}$ and the $\beta$ patterns recorded at $-40{ }^{\circ} \mathrm{C}$ are presented in red and blue lines, respectively. The patterns were shifted for clarity.

corresponding to the $P 1$ space group is more tangible for the two metastable forms, we propose that the latter polymorphs crystallize in the triclinic $P 1$ lattice at that stage of the study. The cell parameters are gathered in Table 3 . However, a single crystal structural survey of these polymorphs could provide more information concerning the statistical occupancy for each molecule within the unit cell. ${ }^{25,26}$

Table 3 Refined cell parameters of $\beta$ enantiomeric and racemic menthol at $-40{ }^{\circ} \mathrm{C}$ from the XRPD experiments

\begin{tabular}{|c|c|c|c|c|}
\hline & & & $\beta$ L menthol & $\beta$ DL menthol \\
\hline Cryst. syst. & & & Triclinic & Triclinic \\
\hline Space group & & & & \\
\hline \multirow[t]{6}{*}{ Unit cell dimension } & Length $(\AA)$ & $a$ & $21.4144(18)$ & $21.6466(29)$ \\
\hline & & $b$ & $12.658(9)$ & $12.7477(16)$ \\
\hline & & $c$ & $6.054(13)$ & $5.9565(6)$ \\
\hline & Angle (deg.) & $\alpha$ & $83.245(16)$ & $84.051(5)$ \\
\hline & & $\beta$ & $96.046(18)$ & $97.144(5)$ \\
\hline & & $\gamma$ & $90.989(8)$ & $90.947(7)$ \\
\hline Volume $\left(\AA^{3}\right)$ & & & 1620.54 & 1622.11 \\
\hline & & & 6 & 6 \\
\hline$D_{\mathrm{c}}\left(\mathrm{g} \mathrm{cm}^{3}\right)$ & & & 0.961 & 0.960 \\
\hline Rwp & & & $4.60 \%$ & $2.93 \%$ \\
\hline
\end{tabular}

As a matter of fact, both $\mathrm{L}$ and DL menthol $\beta$ polymorphs crystallize in a triclinic lattice, which is also the case for $\alpha$ DL menthol, as discussed above. Interestingly, the $\beta \rightarrow \alpha$ transition of $\mathrm{L}$ menthol induces a structural modification of its lattice structure from triclinic to trigonal ( $\alpha$ L menthol space group ${ }^{24}$ : $P 3_{1}$ ). Furthermore, it is noteworthy that the density of $\beta$ DL menthol is lower than that of $\alpha$ DL menthol at a given temperature. However, due to the many degrees of freedom for the molecules within the metastable enantiomer or racemic menthol lattice (translation, rotation and torsion angles), and since the corresponding single crystals have not yet been isolated, we were unable to find their respective crystal structure. Menthol polymorphism seems to be too complex to be elucidated in a quantitative way. The fact that racemic menthol and its enantiomers have distinguishable polymorph structures and behaviors supports this assertion. Even so, at this stage, it is not possible to confirm or deny the fact that both $\alpha$ and $\beta$ DL menthol are mixed crystals. Reconsidering the menthol phase diagrams should give more insights into this. In order to obtain more information related to these menthol forms, and to apprehend the nature of the interactions between $\mathrm{D}$ and $\mathrm{L}$ menthol, binary mixtures with different molar fractions were studied. 


\section{L-menthol/D-menthol phase diagrams: influence of the polymorphism}

Depending on the preparation method of the menthol mixtures, i.e. from the molten state or from the solid state, distinguishable solid liquid equilibria (stable vs. metastable) can be reached due to the polymorphism duality of the pure compounds. Such equilibria were investigated by thermal analysis.

3.1. Stable phase diagram. The DSC thermograms of the mixtures, obtained by mechanical grinding of the pure com pounds in a cold room at $3{ }^{\circ} \mathrm{C}$ and then by annealing them at the same temperature for one month, are presented in Fig. 6. From these results, the corresponding $T x$ phase diagram has been established and is proposed in Fig. 7A. As a matter of fact, the stable phase diagram between the two enantiomers was achieved using DL with $\mathrm{L}$ and D menthol mixtures. The binary system presents eutectic behavior. The coordinates of the eutectic points were found to be equal to $x_{1} \quad 0.29$ and $x_{2} \quad 0.71$ at $29.8^{\circ} \mathrm{C}$, i.e. they are symmetric compared to the equimolar composition vertical axis. These results were confirmed by the Tammann plot (Fig. 7B). The thermal studies indicate that the eutectic invariant does not reach the pure enantiomer part. These results imply that solid solutions should be formed for mixtures enriched with the menthol enantiomers.

Assuming the experimental liquidus data is non ambiguous, the $(\mathrm{d} T / \mathrm{d} x)_{\text {liquidus }}$ van't Hoff equation ${ }^{27}$ term corresponding to the liquidus initial slope was determined for $x$ tending towards 0 or 1 . The solidus initial slope, $(\mathrm{d} T / \mathrm{d} x)_{\text {solidus, }}$, can thus be calculated. The two corresponding slopes are shown in Fig. 7A. The $(\mathrm{d} T / \mathrm{d} x)_{\text {solidus }}$ values obtained for $x$ tending to 0 and 1 ( 44.9 and $44.9{ }^{\circ} \mathrm{C}$, respectively) indicate that the initial slope of the solidus is not colinear to the temperature axis. This result confirms the existence of a solid solution, total miscibility in the solid state, near the pure enantiomer rich part of the phase diagram.

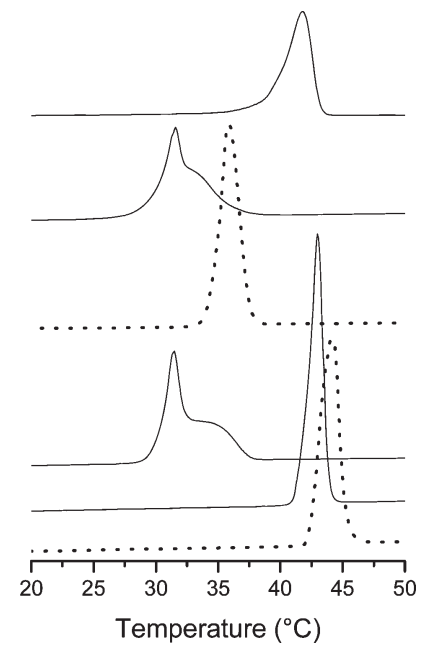

Fig. 6 Weight normalized DSC thermograms of L/D menthol mix tures. D menthol mole fractions: $0.00,0.01,0.37,0.77$ and 0.97 from the bottom to the top curves, respectively. Scan rate: $5{ }^{\circ} \mathrm{C} \min { }^{1}$. The thermograms were shifted for clarity. The dotted lines correspond to the thermograms of the pure compounds. Endothermic transformations give signals which point up.
$\mathbf{A}$

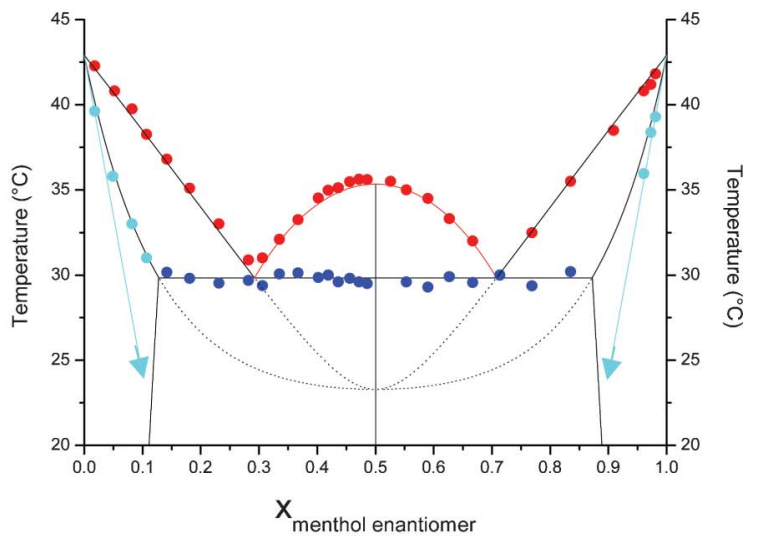

B

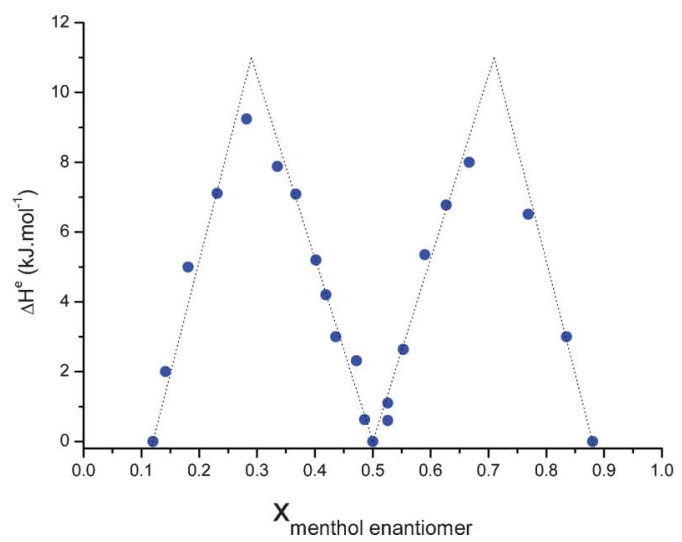

Fig. 7 (A) Temperature composition solid liquid stable phase diagram of the L/D menthol binary system. $x_{\text {menthol enantiomer }}$ stands for the dextrorotatory enantiomer composition. The experimental data obtained from the thermograms are represented by the solid circles. The Prigogine Defay ideal behavior and the simulation from the experi mental data are represented as red solid lines and black lines, respectively. The dotted black lines represent the extrapolation corre sponding to a non stable state of the solid solution: Roozeboom's type III melting loop obtained from the two enantiomers in their stable state. The solidus initial slope is represented by the cyan arrow. The Tammann plot related to the eutectic equilibrium is proposed in panel (B).

In addition, the stable phase diagram reveals that the eutectic invariant tends to $x \quad 0.5$ at $29.8{ }^{\circ} \mathrm{C}$, indicating that any solid solution exists near the equimolar composition. As a conse quence, the equimolar compound, namely $\alpha$ DL menthol, has to be considered as a racemate instead of a mixed crystal, as reported by Kuhnert Brandstaetter et al. ${ }^{14}$

The ideal solubility curve of the racemate, calculated using the Prigogine relation, ${ }^{15,28}$ is indicated as a red solid line in Fig. 7A. The first outcome of the results is that there is no deviation of the experimental points from the ideal liquidus behavior. One can thus consider the menthol liquid mixture as ideal. Furthermore, the racemate presents a congruent melting point, as expected from the thermal study of the $\alpha$ DL menthol detailed above.

As far as the phase equilibrium is concerned, the stable diagram between $\mathrm{L}$ and $\mathrm{D}$ menthol results from the overlapping of the racemate solubility curve with a solid solution Roozeboom's type III melting loop (Fig. 7A). ${ }^{28}$ The melting 
loop, with a minimum temperature, was obtained after fitting the liquidus experimental points obtained for the enantiomer rich compositions. The fitting was achieved by taking into account i) an ideal liquid state, and ii) an excess Gibbs energy in the solid state $\left(G^{\mathrm{exc}, \mathrm{sol}}\right)$ equal to $0.875 \mathrm{~kJ} \mathrm{~mol}^{1}$ for $x \quad 0.5$, where the minimum temperature is reached in such a system. As a consequence, at $29.8{ }^{\circ} \mathrm{C}$, the solid solutions between the two menthol enantiomers were found to be comprised of between 0.00 and 0.13 mole fractions on one side of the diagram and between 0.87 and 1.00 molar fractions on the other side.

Since the Roozeboom's type III melting loop reaches a minimum temperature at $23.3{ }^{\circ} \mathrm{C}$ for $x \quad 0.50$, this extrapolated temperature may be said to correspond to the melting point of a new equimolar menthol phase, since its value significantly differs from the $\beta$ DL menthol melting point $\left(27.3^{\circ} \mathrm{C}\right)$. Referring to Kipping and Pope's concept, ${ }^{29}$ this new phase, a solid solution of an equimolar mixture of enantiomers, is also known as a pseudo racemate, ${ }^{30}$ which corresponds to a polymorph $\left(\mathrm{PR}_{1}\right)$ of racemic menthol. This result was confirmed by the study of the metastable L /D menthol phase diagram.

3.2. Metastable phase diagram. After recrystallization, induced by the thermal quenching of the molten menthol mixtures from 60 to $15^{\circ} \mathrm{C}$ or $80{ }^{\circ} \mathrm{C}$ followed by a $5{ }^{\circ} \mathrm{C}$ min ${ }^{1}$ heating process, the metastable L /D menthol phase diagram was established. Interestingly, the mixtures annealed at $15{ }^{\circ} \mathrm{C}$ from the liquid state, form a solid solution in the whole range of concentrations (Fig. 8). Such behavior was described a few years ago by Gallis and coworkers for L /D carvone ${ }^{31}$ and limonen ${ }^{32}$ mixtures.

The thus obtained Roozeboom's type III melting loop intercepts the pure enantiomer axes at $T \quad 35.3{ }^{\circ} \mathrm{C}$, as previously suggested. ${ }^{14}$ This melting point can be associated with the melting point of the $\beta$ menthol enantiomers without much ambiguity. Taking into account the thermal properties of the $\beta$ menthol enantiomers (Table 2) and assuming the liquid state to be ideal, the fitting of the corresponding experimental data is obtained by using an excess Gibbs energy in the solid state ( $G^{\text {exc,sol }}$ ) equal to $0.275 \mathrm{~kJ} \mathrm{~mol}^{1}$ at the equimolar composition. As a matter of fact, the lowest point of the melting loop is set at $x \quad 0.5 ; T_{\text {fus }} \quad 27.4{ }^{\circ} \mathrm{C}$, which corresponds to the melting data of $\beta$ DL menthol. In order to obtain more insights into the physical properties of this equimolar compound polymorph, XRDP experiments were performed on the binary mixtures with different mole fractions. The cell parameters (lengths, angles) were calculated by following the procedure described in the Materials and experiments section. The evolution of these parameters as a function of the mole fraction is given in Fig. 9. Since no discontinuity in the unit cell parameters evolution is noticed in the whole range of the mole fractions, the equimolar compound polymorph corresponds to a mixed crystal (named $\mathrm{PR}_{2}$ in the present study).

However, $\mathrm{PR}_{2}$ is obtained from $\mathrm{DL}$ menthol in the molten state. As the ideality in the liquid state is directly related to the racemate total dissociation after melting, ${ }^{15,28,34}$ the assumption of an ideal liquid state for the fitting of the metastable menthol phase diagram is then justified. Moreover, it has to be noticed that mixtures of $\mathrm{L}$ and $\mathrm{D}$ menthol, treated in the same way, i.e. a co melting recrystallization process, led to the same metastable phase diagram (Fig. 8). Concerning the annealing temperature,
A

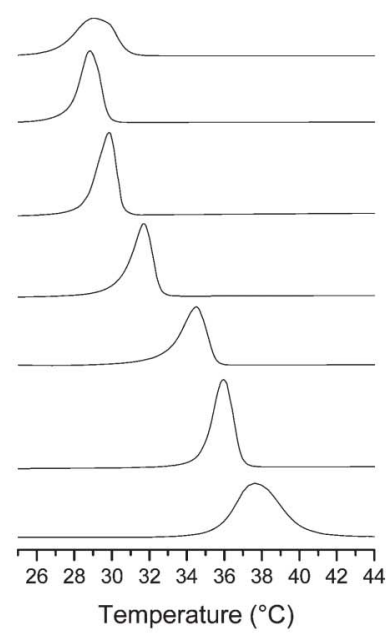

B

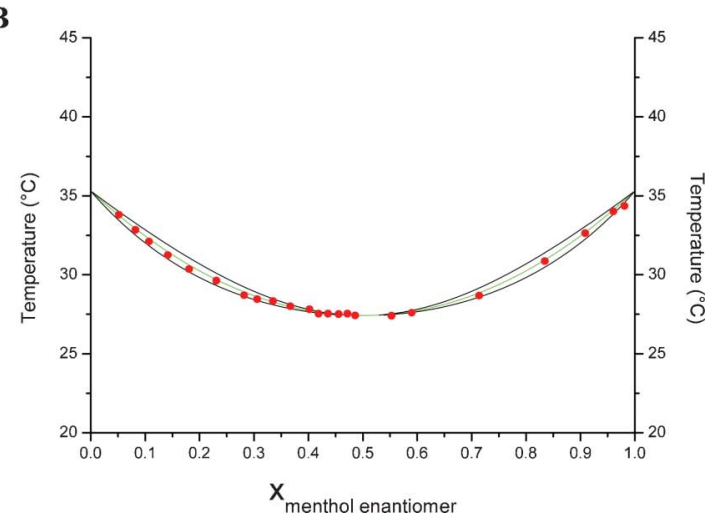

Fig. 8 (A) Weight normalized DSC thermograms of L /D menthol mixtures recorded after quenching the samples from 60 to $15{ }^{\circ} \mathrm{C}$. D menthol mole fractions: $0.00,0.05,0.08,0.18,0.28,0.37$ and 0.50 from the bottom to the top curves, respectively. Scan rate: $5^{\circ} \mathrm{C}$ min ${ }^{1}$, except for the pure menthol enantiomer sample: $20{ }^{\circ} \mathrm{C}$ min ${ }^{1}$. For clarity, the thermograms were shifted and the one corresponding to pure D menthol $(x=0.00)$ was divided by 3 . Endothermic transformations give signals which point up. (B) Temperature composition solid liquid metastable phase diagram of the L /D menthol binary system. $x_{\text {menthol enantiomer }}$ stands for the dextrorotatory enantiomer composition. The experimental data obtained from the thermograms is represented by the solid circles. The simulation from the experimental data leads to the Roozeboom's type III melting loop, obtained from the two enantiomers in their metastable state. The equal G curve, EGC, is shown as a green solid line. The EGC represents the set of points for the intersection of the solid and liquid $\mathrm{G}$ curves in equilibrium at a given temperature. ${ }^{33}$

we also proved that the same recrystallized solid phase was obtained at $15{ }^{\circ} \mathrm{C}$ or $80{ }^{\circ} \mathrm{C}$.

\section{Relative stability of the menthol solid solutions}

The existence of the two menthol solid solutions described above implies that the different polymorphs of the terpene enantiomers may present complete miscibility in the solid state. In such a case, enantiomer $\alpha$ and the pseudo racemate $\mathrm{PR}_{1}$, on the one hand, and enantiomer $\beta$ and pseudo racemate $\mathrm{PR}_{2}$, on the other hand, are isomorphous (Fig. 10). At the equimolar composition, the solid solution obtained from the D and L menthol $\alpha$ phases and the solid solution obtained from their $\beta$ phases present close 

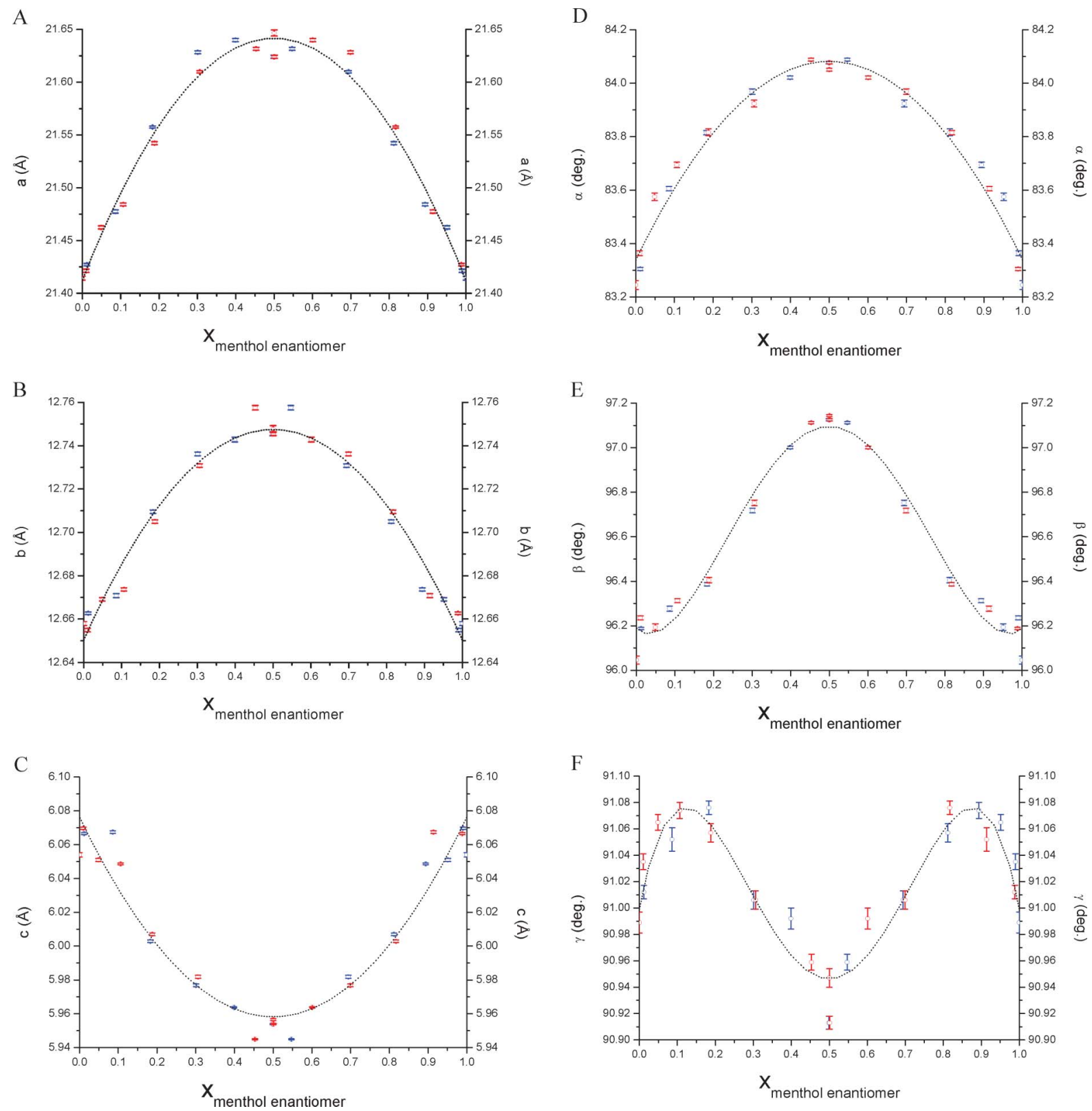

Fig. 9 Evolution of the unit cell parameters as a function of the mole fraction of the menthol enantiomers at $-40{ }^{\circ} \mathrm{C}$. The experimental data is represented in blue. The red points were obtained by symmetry of the blue points with respect to the line $x=0.5$.

melting temperatures. Therefore, in order to have access to the relative stability of the pseudo racemates, the Gibbs energy in the solid state was compared, taking into account the excess quantities previously determined. The excess Gibbs energy, at the equimolar composition, equals $0.875 \pm 0.009$ and $0.275 \pm$ $0.003 \mathrm{~kJ} \mathrm{~mol}{ }^{1}$ for $\mathrm{PR}_{1}$ and $\mathrm{PR}_{2}$, respectively. It turns out that $G^{\mathrm{PR} 1, \mathrm{sol}}\left(\begin{array}{ll}x & 0.5\end{array}\right)>G^{\mathrm{PR} 2, \mathrm{sol}}\left(\begin{array}{ll}x & 0.5\end{array}\right)$. In other words, whereas the $\alpha$ phase of the pure enantiomers is more stable than the $\beta$ phase, $\mathrm{PR}_{2}\left(\beta_{\mathrm{DL}}\right)$ is interestingly more stable than $\mathrm{PR}_{1}$ (Fig. 10). As shown previously, the $\alpha_{D L}$ polymorph is, in any case, a pseudo racemate.

The melting diagram between $\beta_{\mathrm{L}}$ and $\mathrm{PR}_{2}$ (red curve, Fig. 10) is below the solubility curve of $\alpha_{\mathrm{DL}}$ (green curve, Fig. 10) for $0.29 \leqslant x \leqslant 0.50$ and below the $\alpha_{L} / \mathrm{PR}_{1}$ melting loop for $0.00 \leqslant x$ $\leqslant 0.29$. This explains why the $\beta_{\mathrm{L}} / \mathrm{PR}_{2}$ melting loop does not present any stability domain in the stable phase diagram. Indeed, in the upper part of the stable phase diagram, only the $\alpha_{\mathrm{L}}$ liquidus and the $\alpha_{\mathrm{DL}}$ solubility curve converge to the eutectic point.

When mixing the same amount of the two optical menthol enantiomers in their solid state, one can observe that the freshly ground sample exhibits a unique endothermic signal on heating (Fig. 11). This peak can be easily attributed to the "isothermal" fusion of the sample at $28.4{ }^{\circ} \mathrm{C}$ with an associated enthalpy of $\sim 10.4 \mathrm{~kJ} \mathrm{~mol}{ }^{1}$. Since these values are close to those previously found for $\beta$ DL menthol $\left(T_{\text {fus }} \quad 27.3^{\circ} \mathrm{C}, \Delta_{\text {fus }} H \quad 9.3 \mathrm{~kJ} \mathrm{~mol}{ }^{1}\right)$, the freshly prepared sample can be identified as the same phase (i.e. $\mathrm{PR}_{2}$ or $\beta$ DL menthol). The grinding effects, such as amorphization and/or homogenization, could contribute to the slight discrepancy in the temperature and enthalpy data. 


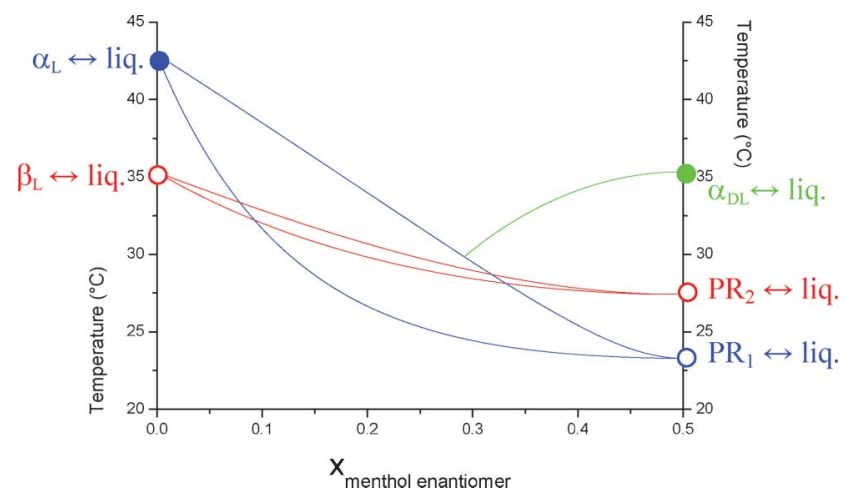

Fig. 10 The melting temperatures as a criterion of the relative stability of the menthol phases for the enantiomer, the racemate and their polymorphs (stable phase: full circle, and the metastable phase: empty circle). Blue curve: melting loop between the $\alpha$ enantiomer and the metastable DL menthol pseudo racemate $\mathrm{PR}_{1}$, due to their complete miscibility in the solid state. Red curve: melting loop between the $\beta$ enantiomer and the pseudo racemate $\mathrm{PR}_{2}\left(\beta_{\mathrm{DL}}\right)$ due to their complete miscibility in the solid state. Green curve: solubility curve of $\alpha$ DL menthol.

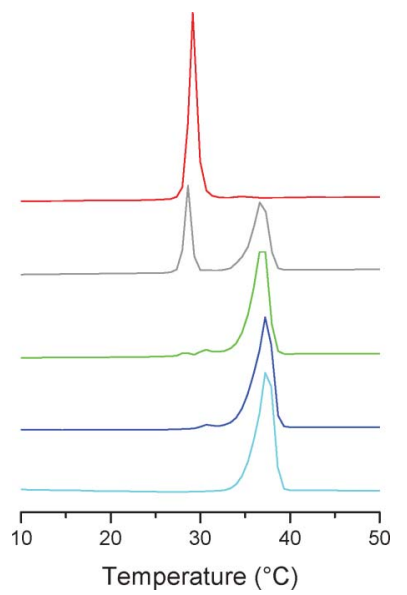

Fig. 11 Thermograms of the D /L menthol mixtures prepared by solid solid grinding in equimolar proportions and annealed at $20{ }^{\circ} \mathrm{C}$. Time after the sample preparation (in h): 0 (red line), 18 (black line), 26 (green line), 93 (dark blue line), and 936 (cyan line). Scan rate: $5{ }^{\circ} \mathrm{C}$ min ${ }^{1}$. Endothermic transformations give signals which point up.

Interestingly, the $\mathrm{PR}_{2}$ kinetics of transformation can be followed by thermal analysis as a function of time after grinding (Fig. 11). It appears that this initial pseudo racemate, $\beta$ DL menthol, progressively disappears and a new phase appears. The latter melts at a temperature of $\sim 34.0{ }^{\circ} \mathrm{C}$. After $936 \mathrm{~h}, \mathrm{PR}_{2}$ has completely disappeared and only the new phase is present. The melting enthalpy of this phase is found to be $14.1 \mathrm{~kJ} \mathrm{~mol}{ }^{1}$. Both values (the melting temperature and enthalpy) indicate that this new phase can be identified as the $\alpha$ menthol racemate.

\section{Conclusions}

In this work, the physico chemical properties of one of the terpenes most used in our daily life, namely menthol, has been thoroughly determined, giving new insight into the stability condition of the compound regarding temperature and/or its interaction with other menthol molecules. The structure of DL menthol was solved from single crystal $\mathrm{X}$ ray diffraction experiments and we showed that the hydrogen of the hydroxyl moiety is shared between two menthol molecules. In addition, menthol polymorphism has been highlighted with new structural and thermodynamic data concerning the $\beta$ form of the levorotatory and racemic compounds that had only been qualitatively described until the present work. Moreover, the nature of the stable phase of DL menthol is undoubtedly given as a crystalline addition compound. The quantitative results obtained allowed us to apprehend and discuss the nature of the interactions between $\mathrm{L}$ and $\mathrm{D}$ menthol via the temperature composition phase diagrams established between the two molecules. The DL menthol pseudo racemate behavior, regard ing its metastability toward stability kinetics, was also approached. Our data provides some original physico chemical information about enantiomeric and racemic (racemate and pseudo racemates) menthol, which could be of interest in many fields, such as biomedical research, but also for the food, cosmetic, chemical and pharmaceutical industries, where menthol is often employed for its taste, smell, cooling or permeation enhancer properties.

\section{Acknowledgements}

We thank Ms. N. Scornet for her contribution as a third year BSc student trainee to this work and Ms. G. Arnaud Vincent for her fruitful discussions and advice on this manuscript. This work was supported in part by the Agence Nationale de la Recherche, NPLIN 4 Drug project.

\section{References}

1 H. G. Brittain, J. Pharm. Sci., 2011, 100, 12601279.

2 J. Bernstein in Polymorphism in molecular crystals, Oxford University Press, New York, 2002.

3 Polymorphism in the pharmaceutical industry, ed. R. Hilfiker, Wiley VCH, Weinheim, 2006

4 A. E. Zavadskii, Fibre Chem., 2007, 39, 483487.

5 I. M. Zakharova and A. E. Zavadskii, Fibre Chem., 2007, 39, 443444.

6 Y. Mo, L. Dang and H. Wei, Ind. Eng. Chem. Res., 2011, 50, 1038510392.

7 J. W. Hagemann in Crystallization and polymorphism of fats and fatty acids, Marcel Dekker, New York, 1988.

8 J. Aronhime, S. Sarig and N. Garti, Food Struct., 1990, 9, 337352.

9 C. Himawan, V. M. Starov and A. G. F. Stapley, Adv. Colloid Interface Sci., 2006, 122, 333.

10 W. W. Porter III, S. C. Elie and A. J. Matzger, Cryst. Growth Des., 2008, 8, 1416.

11 W. M. Coleman III, T. A. Perfetti and R. L. Suber, Jr., J. Chromatogr. Sci., 1998, 36, 318321.

12 S. P. Bhatia, D. McGinty, C. S. Letizia and A. M. Api, Food Chem. Toxicol., 2008, 46, S215 S217.

13 F. E. Wright, J. Am. Chem. Soc., 1917, 39, 15151524.

14 M. Kuhnert Brandstaetter, R. Ulmer and L. Lanaghammer, Arch. Pharm., 1974, 307, 497503.

15 Y. Corvis, P. Negrier, M. Lazerges, S. Massip, J. M. Leger and P. Espeau, J. Phys. Chem. B, 2010, 114, 54205426.

16 Mercury $2.2 \mathrm{http}: / /$ www.ccdc.cam.ac.uk/mercury/.

17 Materials Studio Modeling 4.2 (http://accelrys.com/products/materi als studio/.

18 L. J. Farrugia, J. Appl. Crystallogr., 1997, 30, 565.

19 G. M. Sheldrick, Acta Crystallogr., Sect. A: Found. Crystallogr., 2008, A64, 112122.

20 M. A. Neumann, J. Appl. Crystallogr., 2003, 36, 356365.

21 G. S. Pawley, J. Appl. Crystallogr., 1981, 14, 357361. 
22 H. Sun, J. Phys. Chem. B, 1998, 102, 73387364.

23 J. A. Bouwstra, N. Brouwer, A. C. G. Van Genderen and H. A. J. Oonk, Thermochim. Acta, 1980, 38, 97107.

24 P. Bombicz, J. Buschmann, P. Luger, N. X. Dung and C. B. Nam, Z. Kristallogr., 1999, 214, 420423.

25 C. P. Brock and J. D. Dunitz, Chem. Mater., 1994, 6, 11181127.

26 G. Coquerel, Enantiomer, 2000, 5, 481498.

$27 \mathrm{H}$. Okamoto and T. B. Massalski, Correct and Incorrect Phase Diagram Features in "Methods for Phase Diagram Determination", ed. J. C. Zhao, Elsevier, New York, pp. 51107.

28 I. Prigogine and R. Defay in Thermodynamique Chimique, Tome II, Dunod, Paris, 1946
29 F. S. Kipping and W. J. Pope, J. Chem. Soc., Trans., 1897, 71, 9891001.

30 J. Jacques, A. Collet and S. H. Wilen in Pseudoracemates. Solids Solutions of Enantiomers in "Enantiomers, Racemates, and Resolutions", John Wiley \& sons, New York, pp. 104131.

31 H. E. Gallis, P. J. van Ekeren, J. C. van Miltenburg and H. A. J. Oonk, Thermochim. Acta, 1999, 326, 8390.

32 H. E. Gallis, J. C. van Miltenburg and H. A. J. Oonk, Phys. Chem. Chem. Phys., 2000, 2, 56195623.

$33 \mathrm{H}$. A. J. Oonk in Phase Theory: the Thermodynamics of Heterogeneous Equilibria, Elsevier, New York, pp. 71.

34 R. P. Rastogi and R. K. Nigam, J. Phys. Chem., 1960, 64, 722 726. 